\title{
Thoracolumbar Vertebral Injuries with Neurological Deficit Treated with Posterior Decompression, Short Segment Pedicle Screw Fixation, and Interlaminar Fusion
}

\author{
Sachin Kumar $^{1}$, Satish Kumar $^{1}$, Rajender Kumar Arya ${ }^{1}$, Avinash Kumar $^{2}$ \\ ${ }^{1}$ Departmemt of Orthopedics, Post Graduate Institute of Medical Education and Research and Dr Ram Manohar Lohia Hospital, New Delhi, India \\ ${ }^{2}$ Department of Orthopedics, Post Graduate Institute of Medical Education and Research, Chandigarh, India
}

Study Design: Prospective clinical study.

Purpose: The purpose of this study was to evaluate the effect of interlaminar fusion and short segment pedicle screw fixation on thoracolumbar vertebral injuries for preventing pain and post-traumatic kyphosis.

Overview of Literature: The treatment of thoracolumbar injuries continues to be one of the most controversial areas in spine care. The main aim of surgical treatment is to decompress the spinal cord or nerve roots, realign the spine, and correct or prevent posttraumatic kyphosis. We evaluated the outcome of interlaminar fusion along with posterior decompression and short segment pedicle screw fixation in patients with thoracolumbar fractures with neurological deficit.

Methods: Twenty-two patients with traumatic thoracolumbar vertebral injuries and neurological deficit underwent short segment pedicle screw fixation above and below the fractured vertebrae, posterior decompression, and interlaminar fusion using a bone graft. Results: All patients were followed up for 12 months postoperatively. The average operative time and blood loss was 142 minutes and $214 \mathrm{~mL}$, respectively. Of the 22 patients, 14 recovered completely. Of the nine patients with American Spinal Injury Association (ASIA) grade A disease, two improved by 1 grade, whereas one each improved by grades 2, 3, and 4, and four did not recover. Radiologically, vertebral kyphosis angle improved from 20.91 preoperatively to 15.73 postoperatively, sagittal index improved from 24.77 to 18.73 , the sagittal plane kyphosis angle improved from 17.45 to 11.41 , regional angle kyphosis improved from 14.73 to 10.14 , the superior inferior end plate angle from 16.14 to 13.00 , and mean anterior body compression improved from 36.26 to 27.64 postoperatively. No implant failed and no patient had neurological deterioration.

Conclusions: Short segment pedicle screw fixation with posterior decompression and interlaminar fusion provided considerable reduction in kyphosis, restored the vertebral height of patients with thoracolumbar vertebral injuries and neurological deficit, and prevented development of delayed kyphotic deformity.

Keywords: Thoracolumbar; Neurologic manifestations

Received Dec 30, 2016; Revised Mar 15, 2017; Accepted Apr 6, 2017

Corresponding author: Sachin Kumar

Department of Orthopedics, PGIMER and Dr Ram Manohar Lohia Hospital, New Delhi 110001, India

Tel: +91-01123404286, E-mail: mail2sachin.vmmc@gmail.com 


\section{Introduction}

The thoracolumbar junction, which is the mechanical transition between the rigid thoracic and flexible lumbar spine, is the most commonly injured site in thoracolumbar vertebral injuries. Falls from a height and motor vehicle accidents remain the prime cause of injury in young individuals [1]. Neurological deficit occurs in $15 \%-20 \%$ individuals who sustain an injury. The indication for surgery and the type of fixation used for thoracolumbar vertebral fractures remain controversial, particularly in patients without neurological deficit. However, for patients with neurological deficit, particularly an incomplete deficit, surgery affords significant advantages in pain relief, mobilization, and pulmonary function [2]. The main aim of surgical treatment is to decompress the spinal canal and nerve roots, realign the spine, correct and prevent development of post-traumatic kyphotic deformity, and provide long-term stability to the injured spinal segment [3]. Prevention of collapse and kyphosis during long-term follow-up remains a concern. The posterior short segment fixation construct represents an attempt to restore the anterior column without the need for anterior plate fixation or strut grafting. It limits the number of spinal segments fixed, causes less soft tissue damage, provides a posterior tension band resisting progression of kyphotic deformity, and provides anterior neutralization of healing fractures. Wide decompression laminectomy should be performed from the pedicle above and to the pedicle below the area compressed by a retropulsed fragment in patients who present with neurological deficit or have more than 50\% canal compromise. However, various reported disadvantages, such as delayed kyphosis [4], instrument failure [5-7], and secondary nerve injury, have emerged after performing pedicle screw fixation alone [4]. Although pedicle screw fixation can temporarily reduce a fractured vertebral body, it cannot support the height of the anterior middle vertebral columns in the long term [8]. Therefore, a bone graft is necessary for sound fusion of the segment. Although posterolateral fusion is the most widely performed technique of thoracolumbar arthrodesis, it requires decortication of the transverse process and facet joint. Compared with posterolateral fusion, interlaminar fusion has the advantages of shorter operative time, less damage to the paraspinal muscles, and less blood loss.

This prospective study was performed to evaluate the efficacy of short segment pedicle screw fixation with pos- terior decompression and interlaminar fusion for correction of kyphosis and its maintenance in the long term.

\section{Materials and Methods}

From November 2011 to February 2013, 22 patients with thoracolumbar vertebral injuries and neurological deficit were studied. The inclusion criterion was a thoracolumbar burst fracture with neurological deficit in patients aged 15-60 years. Exclusion criteria included stable thoracolumbar injuries without neurological deficits, osteoporotic vertebral fractures, traumatic spondylolisthesis, uncooperative and unwilling patients, and patients with comorbidities contraindicating spinal surgery. A thorough clinical examination was performed and neurological deficits were graded on a American Spinal Injury Association (ASIA) scale for each patient. Preoperative supine anteroposterior and lateral radiographs and magnetic resonance imaging were performed for all patients. The patients underwent surgery after informed written consent was obtained, and appropriate investigations and preanesthetic follow-up were performed.

\section{Surgical technique}

All surgical procedures were performed with the patient under general anesthesia in the prone position. A midline approach was used, and the paraspinal musculature was dissected. Short segment pedicle screw fixation was performed with the pedicle screws fixed to the adjacent vertebrae above and below the fracture site (Fig. 1). Then, pedicle screw fixation decompression was performed via hemilaminectomy at the fractured level and on the side

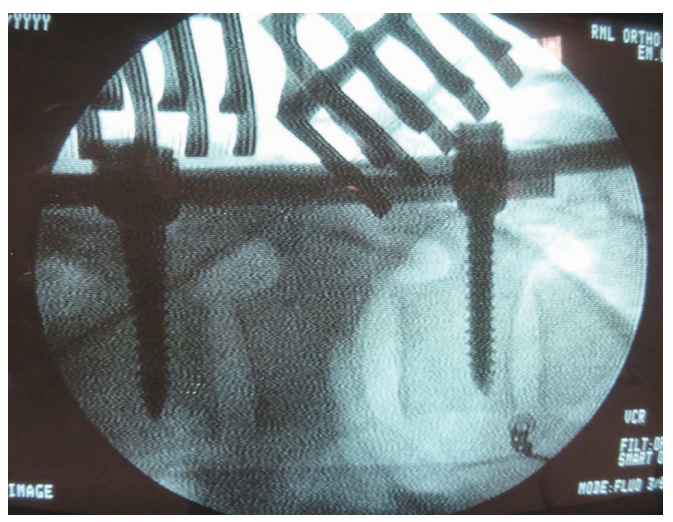

Fig. 1. Placement and confirmation of pedicle screw under C-arm. 
of compression in the vertebral canal. In cases of central compression, central decompression via partial laminectomies on both sides with removal of the spinous process of the affected vertebra was performed. Rods of appropriate length were contoured and inserted into the end screw extender sleeves, and the position was controlled with an image intensifier. Reduction was performed with the help of an interbody distracter and counter torque reduction

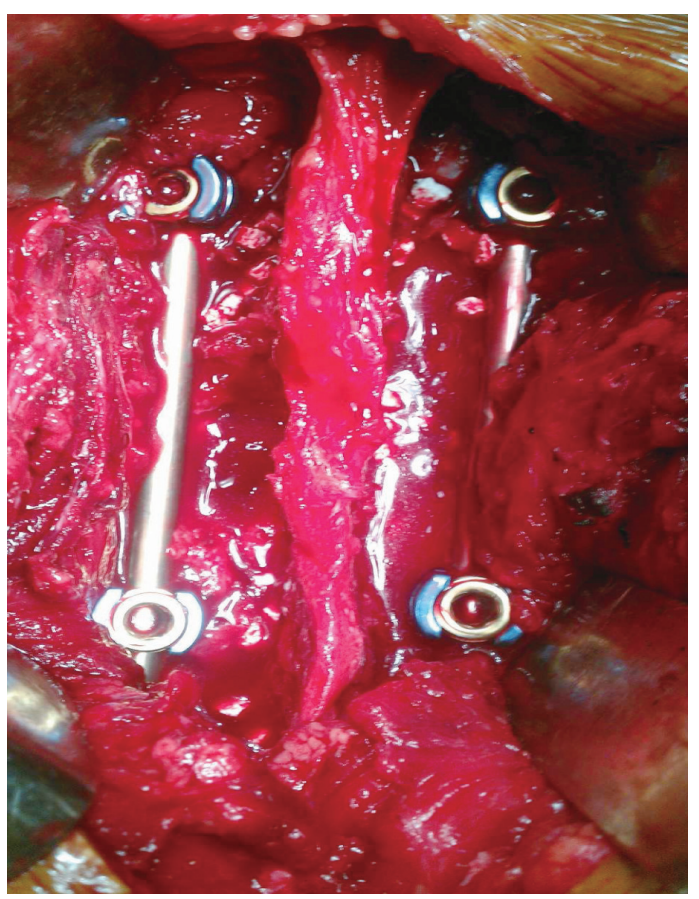

Fig. 2. Interlaminar fusion done with bone graft and bone substitute.

Table 1. Preoperative and postoperative neurologica

\begin{tabular}{lccccc} 
Neurological status & A & B & C & D & E \\
Preoperative neurological status & 9 & 1 & 9 & 3 & 0 \\
Postoperative neurological status (12 mo) & 4 & 2 & 1 & 1 & 14 \\
\hline
\end{tabular}

Table 2. Radiographic changes after surgery

\begin{tabular}{lcccc} 
Duration & Vertebral-angle & Sagittal plane kyphosis & Regional kyphosis angle & Anterior body compression \\
\hline Preoperative & $20.91 \pm 5.614$ & $17.45 \pm 7.076$ & $14.73 \pm 8.270$ & $36.26 \pm 11.058$ \\
\hline Postoperative 1 day & $16.09 \pm 5.927$ & $9.82 \pm 7.462$ & $10.59 \pm 6.185$ & $32.14 \pm 13.513$ \\
\hline Postoperative 6 wk & $16.86 \pm 7.453$ & $12.23 \pm 7.283$ & $10.18 \pm 6.659$ & $29.49 \pm 11.225$ \\
Postoperative 3 mo & $15.68 \pm 5.923$ & $11.27 \pm 7.827$ & $9.86 \pm 6.777$ & $27.79 \pm 11.582$ \\
Postoperative 6 mo & $14.86 \pm 6.243$ & $11.09 \pm 5.967$ & $9.18 \pm 5.654$ & $26.09 \pm 11.801$ \\
\hline Postoperative 12 mo & $15.73 \pm 6.656$ & $11.41 \pm 6.084$ & $10.14 \pm 5.792$ & $27.64 \pm 11.931$ \\
\hline
\end{tabular}

Values are presented as mean \pm standard deviation. 
performing the study, vertebral angle measurements improved from 20.91 to 15.73 ( $p<0.05$, statistically significant), regional angle improved from 14.73 to 10.14 , sagittal plane kyphosis angle improved from 17.45 to 11.41 , and anterior body compression improved from 36.26 to 27.64 (all $p<0.05$, statistically significant) (Tables 2,3 ). Final radiographs and CT showed radiologically healed fractures at the 1-year follow-up along with interlaminar fusion (Figs. 3, 4). No perioperative or postoperative wound complications were reported at the latest followup, and no implant failures occurred in any patient.

\section{Discussion}

Selection of the surgical method for treatment of thoracolumbar burst fractures remains a matter of debate [8-12]. The incidence of spinal fractures is increasing because of road traffic accidents, although the most common mode of trauma in our study was a fall from a height. Other studies also document fall from a height to be the most common mode of injury $[13,14]$. However, Wood et al. [15] noted motor vehicle accidents as the most common cause.
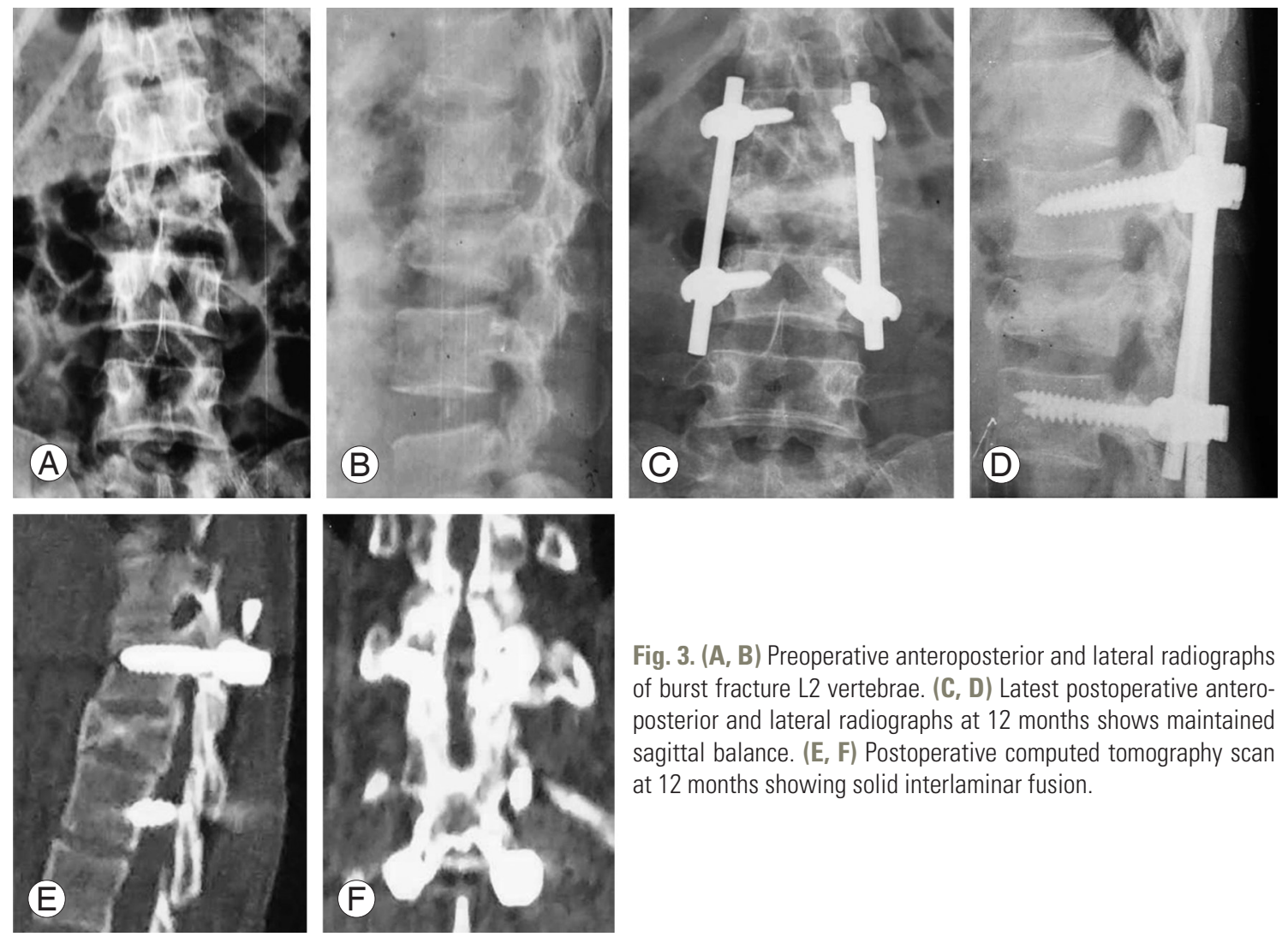

Most fractures in our study were localized in the thoracolumbar region, which corresponded to the findings of many researchers who stated that L1 was the most common site to be affected $[13,14]$. Although Alanay et al. [16] reported T12 as the most common injury level, Farcy et al. [17] noted L2 in males and L1 in females to be the most commonly injured vertebra. In our case, D12, L1, and L2 vertebrae were fractured with the same frequency ( ix cases each), with an $81 \%$ rate of involvement of these three vertebrae. Males are more prone to thoracolumbar fractures than females because they are involved in outdoor activities to a greater extent. Of the males and females in our study, $64 \%$ and $36 \%$, respectively, sustained injuries.

Multiple parameters, such as type and stability of fracture, degree of canal compromise, injury to the posterior ligament complex, and neurological status, must be considered $[8,11,18]$. Short segment fixation is frequently regarded as the procedure of choice because it offers advantages, such as incorporation of fewer motion segments in the fusion, shorter operative time, and fewer blood transfusions. However, without vertebral body reconstruction, short segment pedicle screw fixation has a $9 \%-54 \%$ inci-
Fig. 3. (A, B) Preoperative anteroposterior and lateral radiographs of burst fracture $L 2$ vertebrae. (C, D) Latest postoperative anteroposterior and lateral radiographs at 12 months shows maintained sagittal balance. (E, F) Postoperative computed tomography scan at 12 months showing solid interlaminar fusion. 

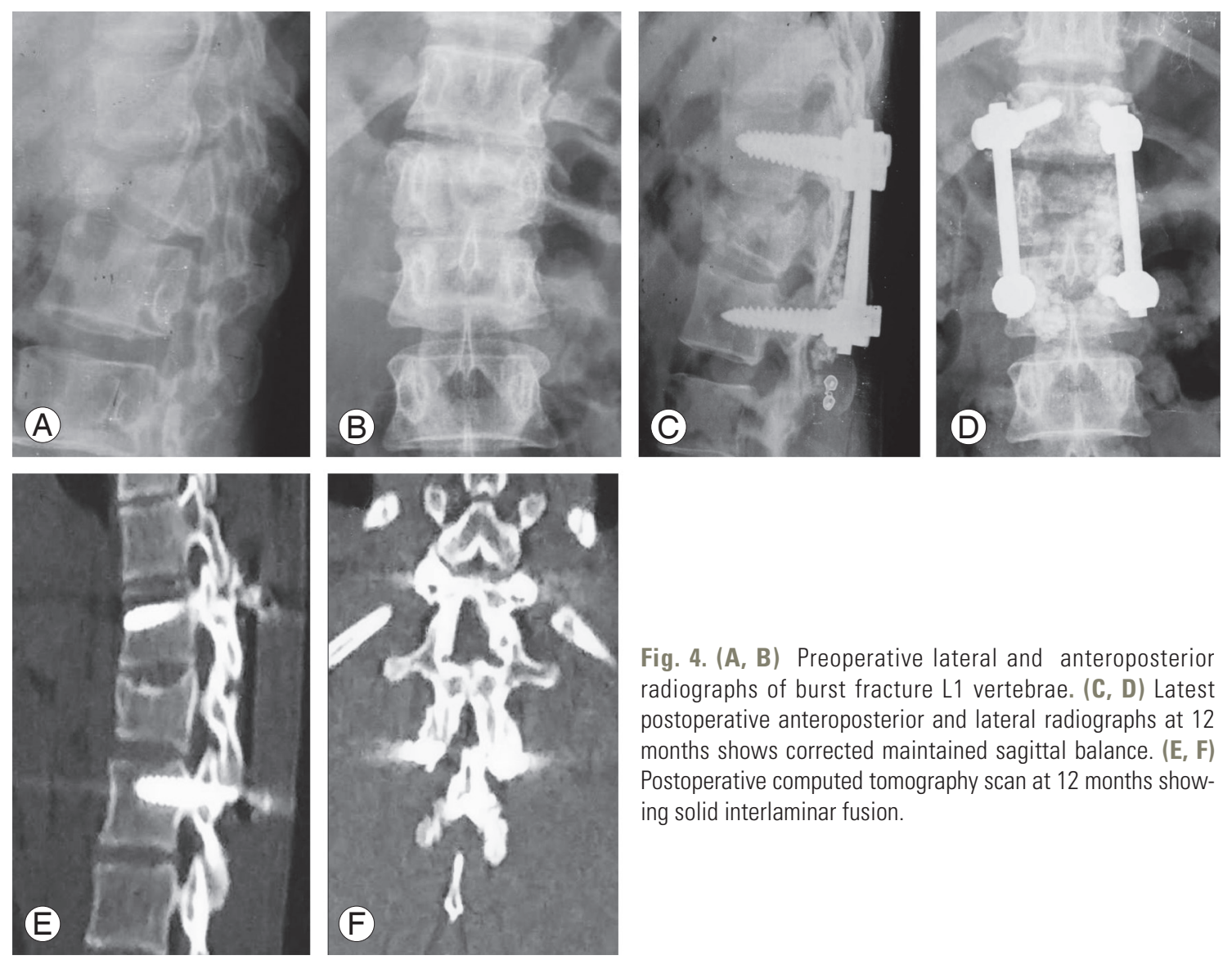

Fig. 4. (A, B) Preoperative lateral and anteroposterior radiographs of burst fracture L1 vertebrae. (C, D) Latest postoperative anteroposterior and lateral radiographs at 12 months shows corrected maintained sagittal balance. $(\mathbf{E}, \mathbf{F})$ Postoperative computed tomography scan at 12 months showing solid interlaminar fusion.

Table 3. Statistical significance table

\begin{tabular}{lccccc} 
& \multicolumn{5}{c}{$p$ p-value } \\
\cline { 2 - 6 } $\begin{array}{l}\text { Radiological } \\
\text { parameters }\end{array}$ & $\begin{array}{c}\text { Preoperative- } \\
\text { postoperative } \\
1 \text { day }\end{array}$ & $\begin{array}{c}\text { Preoperative- } \\
\text { postoperative }\end{array}$ & $\begin{array}{c}\text { Preoperative- } \\
\text { postoperative }\end{array}$ & $\begin{array}{c}\text { Preoperative- } \\
\text { postoperative }\end{array}$ & $\begin{array}{c}\text { Preoperative- } \\
\text { postoperative } \\
12 \text { mo }\end{array}$ \\
Vertebral-angle & 0.013 & 3 mo & 0.007 & 0.002 & 0.008 \\
Sagittal plane kyphosis & 0.001 & 0.036 & 0.004 & 0.003 & 0.005 \\
Regional kyphosis angle & 0.040 & 0.014 & 0.016 & 0.006 & 0.023 \\
Anterior body compression & 0.251 & 0.024 & 0.019 & 0.005 & 0.017 \\
\hline
\end{tabular}

Table 4. Injury surgery time interval

\begin{tabular}{lcc} 
Time interval & Frequency & Percentage \\
$<24 \mathrm{hr}$ & 0 & 0 \\
$1-5$ day & 17 & 77 \\
$6-14$ day & 4 & 18 \\
$15-21$ day & 1 & 5 \\
$>21$ day & 0 & 0 \\
\hline
\end{tabular}

dence of recurrent kyphosis and implant failure $[6,9,19]$.

The interval between the injury and surgery is crucial because it determines the efficacy of ligamentotaxis of the fractured vertebra (Table 4). This process must be completed within a satisfactory interval because the efficacy of ligamentotaxis has been shown to diminish as early as 3 days after traumatic injury [20-22]. Because such patients are generally referred from the periphery to our institution, achieving such a short interval between injury 
and surgery is difficult. Of the patients, 77\% underwent surgery between 1 and 5 days after injury, whereas 95\% patients underwent surgery before day 14 after injury and only 1 patient underwent surgery after day 15 .

It has been speculated that posterior instrumentation fails because of a large bone defect created inside the fractured vertebral body after indirect ligamentotaxis. To prevent this, several techniques have been developed to augment the fractured vertebral body in cases of burst fractures. Transpedicular grafting along with short segment pedicle screw fixation has been suggested by several researchers $[3,23]$, whereas others doubted its usefulness, reporting a correction loss of $2^{\circ}-10^{\circ}[4]$ or warned of a potentially dangerous situation if the graft was not placed carefully $[9,14,24,25]$. Another technique for preventing gradual increase in kyphotic deformity is fracture level screw fixation. Screws at the fracture level provide mass effect and prevent the vertebrae from collapsing. Guven et al. [26] reported good clinical results.

The method of decompression depends on personal choice and experiences of the operating surgeon. An anterior approach permits an unobstructed view of the thecal sac and remains the most reliable method for achieving decompression in patients with an incomplete neurological deficit and significant canal occlusion on axial imaging studies. Anterior decompression with strut grafting and anterior instrumentation yielded good radiographic and functional results in patients with thoracolumbar burst fractures and neurological deficit, according to Kaneda et al. [11]. However, this approach seems to be technically more difficult and carries a risk of injury to the visceral and vascular organs and thus, potential morbidity. Anterior and posterior fixation was compared in 40 patients with a mean follow-up of 20 months and posterior fixation was found to be as effective as anterior fixation, although anterior surgery resulted in a more complete and reliable decompression of the canal. Esses et al. [27] and Danisa et al. [28] have shown that posterior spinal instrumentation involves shorter operative times and decreased blood loss, and functional outcomes are similar to those following anterior surgery for the treatment of thoracolumbar burst fractures.

Thus far, posterolateral fusion along with pedicle screw fixation is considered to be the choice of treatment for thoracolumbar fractures. Schmid et al. [29] reported on posterior lumbar interbody fusion (PLIF) for the treatment of thoracolumbar trauma and have suggested that PLIF avoids potential complications of anterior decompression. However, it has been associated with disadvantages, such as more soft tissue and removal of the posterior element of the vertebrae because it requires exposure and freshening of the transverse processes and facet joints for posterolateral fusion and it is associated with longer operative time as well as greater blood loss. Harms et al developed a transforaminal lumbar interbody fusion (TLIF) technique for treating degenerative disease of the lumbar spine. In addition, Humphreys et al. [30] compared TLIF and PLIF and found that TLIF has a similar operative time, hospital stay, and blood loss as PLIF; has fewer complications than PLIF; maintains normal muscular attachments; and, thus, causes no disruption to the loading mechanics of the spine. Compared with posterolateral fusion, interlaminar fusion has the advantage of a shorter operative time, less blood loss, and less damage to the paraspinous muscles. No hardware failure was reported in our study; thus, we postulated that compared with posterolateral fusion, solid interlaminar fusion was a better addition to posterior instrumentation and prevented failure of the implant.

One limitation of the study was the small sample size, and further randomized controlled trials are needed with more patients in the study.

\section{Conclusions}

Short segment pedicle screw fixation with posterior decompression and interlaminar fusion provided good kyphotic reduction of the fractured vertebrae immediately postoperatively and in the long term and prevented future failure of the spine without extensive dissection and more blood loss as observed with posterolateral bone grafting.

\section{Conflict of Interest}

No potential conflict of interest relevant to this article was reported.

\section{Acknowledgments}

The study is being done at PGIMER \& Dr Ram Manohar Lohia Hospital New Delhi which is a government of India institute and patients being treated in the hospital for free of cost. 


\section{References}

1. Robertson A, Branfoot T, Barlow IF, Giannoudis PV. Spinal injury patterns resulting from car and motorcycle accidents. Spine (Phila Pa 1976) 2002;27:282530.

2. Jacobs PR, Casey MP. Surgical management of thoracolumbar spinal injuries: general principals and controversial considerations. Clin Orthop Relat Res 1984;(189):22-35.

3. Aebi M, Etter C, Kehl T, Thalgott J. Stabilization of the lower thoracic and lumbar spine with the internal spinal skeletal fixation system. Indications, techniques, and first results of treatment. Spine (Phila Pa 1976) 1987;12:544-51.

4. Speth MJ, Oner FC, Kadic MA, de Klerk LW, Verbout AJ. Recurrent kyphosis after posterior stabilization of thoracolumbar fractures: 24 cases treated with a Dick internal fixator followed for 1.5-4 years. Acta Orthop Scand 1995;66:406-10.

5. Kramer DL, Rodgers WB, Mansfield FL. Transpedicular instrumentation and short-segment fusion of thoracolumbar fractures: a prospective study using a single instrumentation system. J Orthop Trauma 1995;9:499-506.

6. McLain RF, Sparling E, Benson DR. Early failure of short-segment pedicle instrumentation for thoracolumbar fractures: a preliminary report. J Bone Joint Surg Am 1993;75:162-7.

7. Butt MF, Farooq M, Mir B, Dhar AS, Hussain A, Mumtaz M. Management of unstable thoracolumbar spinal injuries by posterior short segment spinal fixation. Int Orthop 2007;31:259-64.

8. Wood KB, Bohn D, Mehbod A. Anterior versus posterior treatment of stable thoracolumbar burst fractures without neurologic deficit: a prospective, randomized study. J Spinal Disord Tech 2005;18 Suppl:S15-23.

9. Alanay A, Acaroglu E, Yazici M, Oznur A, Surat A. Short-segment pedicle instrumentation of thoracolumbar burst fractures: does transpedicular intracorporeal grafting prevent early failure? Spine (Phila Pa 1976) 2001;26:213-7.

10. Cho DY, Lee WY, Sheu PC. Treatment of thoracolumbar burst fractures with polymethyl methacrylate vertebroplasty and short-segment pedicle screw fixation. Neurosurgery 2003;53:1354-60.
11. Kaneda K, Taneichi H, Abumi K, Hashimoto T, Satoh S, Fujiya M. Anterior decompression and stabilization with the Kaneda device for thoracolumbar burst fractures associated with neurological deficits. J Bone Joint Surg Am 1997;79:69-83.

12. Sasso RC, Best NM, Reilly TM, McGuire RA Jr. Anterior-only stabilization of three-column thoracolumbar injuries. J Spinal Disord Tech 2005;18 Suppl:S7-14.

13. Leferink VJ, Zimmerman KW, Veldhuis EF, ten Vergert EM, ten Duis HJ. Thoracolumbar spinal fractures: radiological results of transpedicular fixation combined with transpedicular cancellous bone graft and posterior fusion in 183 patients. Eur Spine J 2001;10:517-23.

14. Knop C, Fabian HF, Bastian L, Blauth M. Late results of thoracolumbar fractures after posterior instrumentation and transpedicular bone grafting. Spine (Phila Pa 1976) 2001;26:88-99.

15. Wood K, Buttermann G, Mehbod A, Garvey T, Jhanjee R, Sechriest V. Operative compared with nonoperative treatment of a thoracolumbar burst fracture without neurological deficit: a prospective, randomized study. J Bone Joint Surg Am 2003;85:773-81.

16. Alanay A, Acaroglu E, Yazici M, Aksoy C, Surat A. The effect of transpedicular intracorporeal grafting in the treatment of thoracolumbar burst fractures on canal remodeling. Eur Spine J 2001;10:512-6.

17. Farcy JP, Weidenbaum M, Glassman SD. Sagittal index in management of thoracolumbar burst fractures. Spine (Phila Pa 1976) 1990;15:958-65.

18. Vaccaro AR, Rihn JA, Saravanja D, et al. Injury of the posterior ligamentous complex of the thoracolumbar spine: a prospective evaluation of the diagnostic accuracy of magnetic resonance imaging. Spine (Phila Pa 1976) 2009;34:E841-7.

19. Li KC, Hsieh CH, Lee CY, Chen TH. Transpedicle body augmenter: a further step in treating burst fractures. Clin Orthop Relat Res 2005;(436):119-25.

20. Crutcher JP Jr, Anderson PA, King HA, Montesano PX. Indirect spinal canal decompression in patients with thoracolumbar burst fractures treated by posterior distraction rods. J Spinal Disord 1991;4:39-48.

21. Willen J, Lindahl S, Irstam L, Nordwall A. Unstable thoracolumbar fractures: a study by CT and conventional roentgenology of the reduction effect of Harrington instrumentation. Spine (Phila Pa 1976) 
1984;9:214-9.

22. Yazici M, Gulman B, Sen S, Tilki K. Sagittal contour restoration and canal clearance in burst fractures of the thoracolumbar junction (T12-L1): the efficacy of timing of the surgery. J Orthop Trauma 1995;9:491-8.

23. Hart DA, Archambault JM, Kydd A, Reno C, Frank $\mathrm{CB}$, Herzog W. Gender and neurogenic variables in tendon biology and repetitive motion disorders. Clin Orthop Relat Res 1998;(351):44-56.

24. Sjostrom L, Jakobsson O, Karlstrom G, Pech P. Transpedicular bone grafts misplaced into the spinal canal. J Orthop Trauma 1992;6:376-8.

25. Tagil M, Johnsson R, Stromqvist B, Aspenberg P. Incomplete incorporation of morselized and impacted autologous bone graft: a histological study in 4 intracorporally grafted lumbar fractures. Acta Orthop Scand 1999;70:555-8.

26. Guven O, Kocaoglu B, Bezer M, Aydin N, Nalban- toglu U. The use of screw at the fracture level in the treatment of thoracolumbar burst fractures. J Spinal Disord Tech 2009;22:417-21.

27. Esses SI, Botsford DJ, Kostuik JP. Evaluation of surgical treatment for burst fractures. Spine (Phila Pa 1976) 1990;15:667-73.

28. Danisa OA, Shaffrey CI, Jane JA, et al. Surgical approaches for the correction of unstable thoracolumbar burst fractures: a retrospective analysis of treatment outcomes. J Neurosurg 1995;83:977-83.

29. Schmid R, Krappinger D, Seykora P, Blauth M, Kathrein A. PLIF in thoracolumbar trauma: technique and radiological results. Eur Spine J 2010;19:1079-86.

30. Humphreys SC, Hodges SD, Patwardhan AG, Eck JC, Murphy RB, Covington LA. Comparison of posterior and transforaminal approaches to lumbar interbody fusion. Spine (Phila Pa 1976) 2001;26:567-71. 